\title{
The 2nd International Conference on Engineering of Technology Innovation (ICETI 2012) Kaohsiung, Taiwan, Nov. 2-6, 2012
}

\author{
Wen-Hsiang Hsieh • B. Michel
}

Published online: 1 October 2013

(C) Springer-Verlag Berlin Heidelberg 2013

This Special Issue presents 16 papers selected from the proceedings of the 2nd International Conference on Engineering and Technology Innovation (ICETI 2012) which was held from November 02 to 06, 2012, at the Crowne Plaza Hotel Kaohsiung E-DA World in southern Taiwan. It covers a wide range of fundamental studies, technical innovation and industrial applications by applying the knowledge of various science and technology. All of the papers submitted to the ICETI 2012 were first subject to examination by at least two independent reviewers prior to the conference. From the 80 papers accepted for presentation at the conference, only 20 prominent candidates went through the regular review process of Microsystem Technology. 16 papers were finally accepted for the special issue as revised full length papers representing the interdisciplinary spirit of this event. We hope you will enjoy reading them and take inspiration from their new ideas. Finally, we would like to thank all reviewers and the editorial team for the work making this special issue possible.

W.-H. Hsieh

Conference Chair and Guest Editor,

Department of Automation Engineering,

National Formosa University, Yunlin, Taiwan, ROC

B. Michel ( $₫)$

Editor of MST Journal, Fraunhofer ENAS,

Chemnitz, Germany

e-mail: bernd.michel@coinn.de 